\title{
Splenic Tuberculosis - A Rare Case Report
}

\author{
Authors \\ Dr Thiyam Brojendro Singh, Dr Jafar Niyas, Dr Laikangbam Subhalaxmi, \\ Dr Karam Romeo Singh, Dr Santosh Kumar Singh, Dr Th Bhimo Singh \\ Corresponding Author \\ Jafar Niyas \\ Department of Medicine, Regional Institute of Medical Sciences, Lamphelpat, \\ Imphal West, Manipur, India
}

\begin{abstract}
Involvement of spleen in tuberculosis mostly occurs as a part of miliary tuberculosis especially in immunocompromised individuals. It is extremely rare in the immunocompetent patients and only few cases reported internationally. Here we are reporting a rare case of 35 year old immunocompetent female who presented with evening rise of temperature, decreased appetite \& loss of weight for the last 3 months and recurrent pain in left hypochondrium for one month. On evaluation found to have elevated ESR with a strongly positive mantoux test and multiple hypo echoic lesions in the spleen on ultrasound abdomen. Contrast enhanced computed tomography showed multiple hypodense lesions with significant wall enhancement in the spleen. Fine needle aspiration cytology showed focal areas of caseous necrosis with acid fast bacilli in ZiehlNeelsen stain and the diagnosis of tuberculosis of spleen is confirmed. No primary focus of infection detected in the lungs or any other organs.
\end{abstract}

Keywords: tuberculosis, spleen, immunocompetent.

\section{INTRODUCTION}

There are only few cases of splenic tuberculosis reported internationally in literature. Splenic TB is extremely rare in immunocompetent individuals and has no characteristic symptoms although secondary involvement in miliary TB is common especially in immunocompromised persons. The missdiagnosis rate is also high if there is no tuberculosis history in other organs. Here we are reporting a rare case of splenic tuberculosis in an immunocompetent individual.

\section{CASE REPORT}

A 35 year old woman presented with evening rise of temperature, decreased appetite \& loss of weight for the last 3 months and recurrent pain in left hypochondrium for one month duration. History of contact with an open case of $\mathrm{Tb}$ from the neighbour was there. There was no history of use of immunosuppressants, organ transplant or prior chemotherapy.

Physical examination revealed a moderately build and poorly nourished lady weighing $38 \mathrm{Kg}$, anemic, febrile with no hepato splenomegally on 
palpation. Systemic examination revealed no significant abnormality.

Routine blood analysis showed haemoglobin $9.7 \mathrm{mg} \%$ with total leucocytes count 5700 (Polymorphs 71\%, Lymphocytes 24\%, Monocytes 03\%, Eosinophils $05 \&$ Basophils 0\%) and an elevated erythrocyte sedimentation rate of 115 $\mathrm{mm} / 1$ hour. Peripheral smear showed normocytic hypochromic picture with adequate number of platelets. Other routine biochemical parameters including blood sugar, liver and kidney function tests, urine microscopy and culture, thyroid function tests were within normal limits. ELISA test for HIV, hepatitis B and hepatitis C screenings were negative.

Abdominal ultrasound revealed a normal sized spleen with multiple hypoechoic lesions largest measuring $4 \mathrm{~cm} \times 3.6 \mathrm{~cm}$. Other abdominal organs showed no significant abnormality in ultrasound.

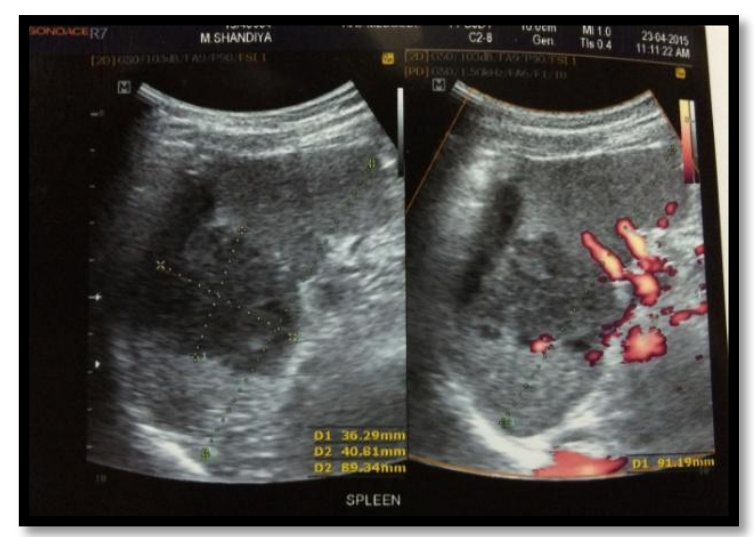

Figure 1: Ultrasound picture of spleen showing multiple hypodense lesions.

Mantoux test showed a strongly positive induration of $35 \mathrm{~mm} \times 30 \mathrm{~mm}$ in diametre.

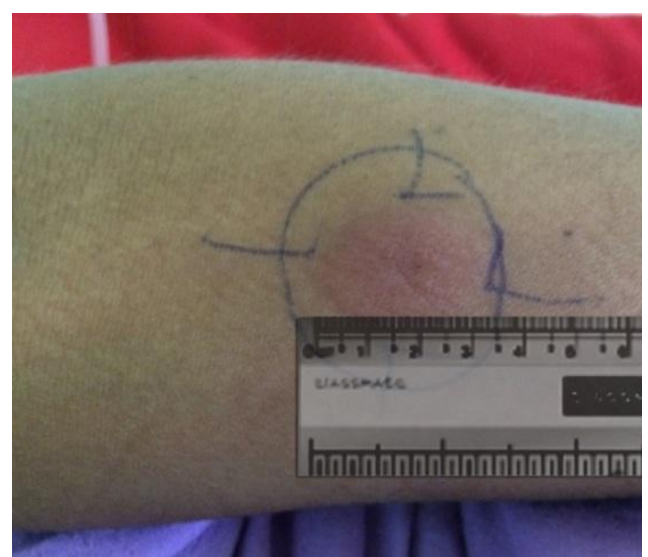

Figure 2: Photograph showing a strongly positive mantaux of $35 \times 30 \mathrm{~mm}$ induration.
Chest X-ray showed no significant abnormality. Contrast enhanced computed tomography revealed multiple hypodense lesions in the spleen, largest measuring $2.7 \mathrm{~cm}$ in the middle portion with small satellite lesions. There was a large subcapsular lesion of $5 \mathrm{~cm} \times 2 \mathrm{~cm}$ in axial dimension. Post contrast images showed significant wall enhancement of the lesion. Liver, kidneys, visualised bowel loops and pelvic organs were within normal limit and there was no free fluid in the peritoneum.

Ultrasound guided fine needle aspiration cytology showed scattered mixed inflammatory cells with focal areas of caseous necrosis and acid fast bacilli in Ziehl-Neelsen stain

On further evaluation there was no other primary foci of tuberculosis in lungs or any other organs .

Anti tubercular therapy with four drug regimen was started and she is responding well to the treatment, afebrile and is on follow up.

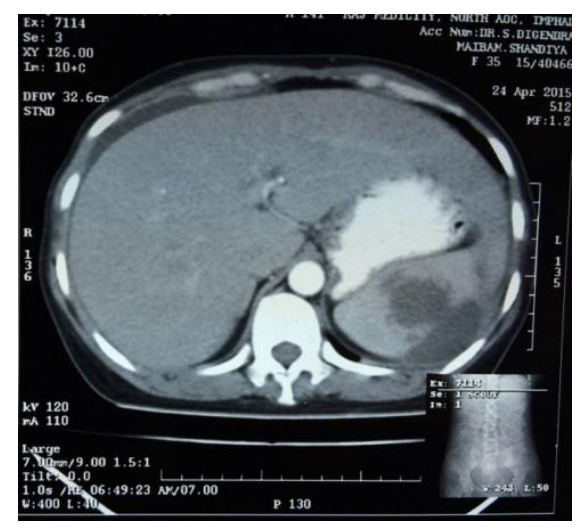

Figure 3: CECT abdomen showing hypodense lesions in the spleen with small satellite lesions

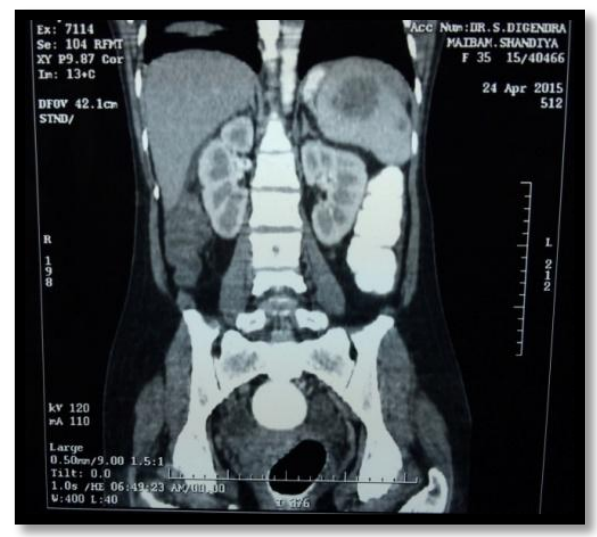

Figure 4: Coronal view CECT abdomen from the same patient showing hypodense lesions in the spleen. 


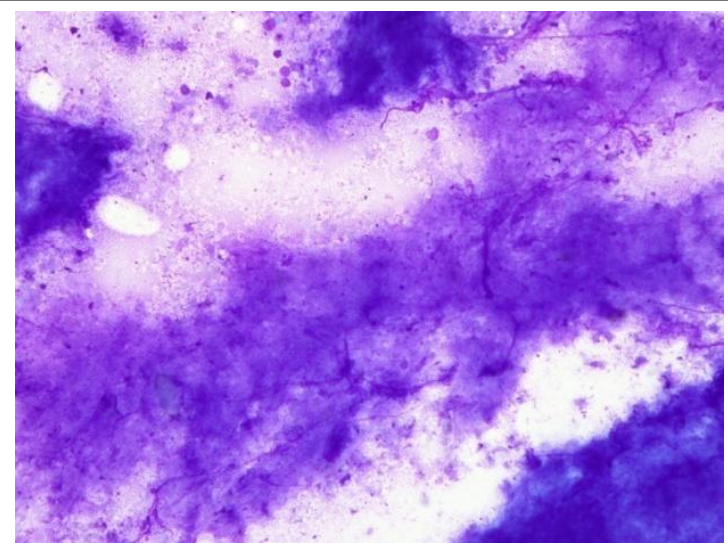

Figure 5: Needle aspiration cytology of spleen showing caseous necrosis

\section{DISCUSSION}

Lung is the major site of involvement of tuberculosis. The extrapulmonary tuberculosis involves $11-16 \%$ of all patients of tuberculosis out of which 3 to $4 \%$ belong to abdominal tuberculosis. ${ }^{1}$ Involement of spleen in tuberculosis usually develops as a result of dissemination of advanced pulmonary or miliary tuberculosis. This is seen usually in immunocompromised individuals like human immuno deficiency virus infection, chronic debilitating diseases or malignancies. ${ }^{2}$ Rarely spleen can be infected through the ingestion of contaminated food or sputum, or by dissemination via portal vein.

Primary involvement of tuberculosis is extremely rare in immunocompetent individuals. Most common presentations are low grade fever, fatigue, weight loss and splenomegally. ${ }^{3,4,6}$ Majority of the cases of splenic tuberculosis is micronodular and is usually associated with involvement of liver also. Macro nodular involvement is extremely rare and it is more frequent associated HIV infected patients with a rate around $15 \% .^{12}$

On ultrasonography micronodular lesions usually seen as diffuse hyperechoic lesions except in cases of necrotising lesions. In computed tomography these lesions typically appear as multiple rounded hypodense leions with a diameter of $1-2 \mathrm{~cm} .^{5}$

In the differential diagnosis of solitary spleen lesions splenic cysts, hemangiomas, hamartomas, pyogenic, amoebic, fungal or tubercular abcess, primary malignancies like lymphoma or metastatic tumors should be considered. ${ }^{4}$ In a suspected cases of splenic lesions ultrasound is the first imaging of choice as it is cheap and reliable. ${ }^{7}$ On the other hand contrast enhanced CT is ideal for establishing the extend of the disease and for evaluating the complications. An ultrasound guided needle aspiration usually reveals a positive results for diagnosis. ${ }^{8}$ The reported yield of aspiration cytology from the splenic lesions is variable. Suri et al reported up to $88 \%$ sensitivity for fine needle aspiration cytology. ${ }^{9}$

However a definite diagnosis of splenic Tb may require a splenectomy and histopathological examination. $^{10}$

Most of the cases of primary splenic $\mathrm{Tb}$ can be managed medically with anti tubercular therapy alone and may require long term treatment especially in immunocompromised patients. ${ }^{11} \backslash$

\section{REFERENCES}

1. Sharma SK, Mohan A. Extrapulmonary tuberculosis. Ind J Med Res 2004;124:31653.

2. Sharma SK, Mohan A, Kadhiravan T. HIV-TB co-infection: Epidemiology diagnosis and management. Ind $\mathrm{J}$ Med Res 2005;121:550-67.

3. Ho PL, Chim CS, Yuen KY. Isolated Sple nic Tuberculosis presenting with pyrexia o f unknown origin. Scand J Infect Dis. 2000 ;32(6):700-1.

4. Johanna V. Basa,Lilly Singh, Wassim Abi Jaoude. A case of isolated splenic tuberculosis. Int J Surg. 2015; 8: 117-119.

5. Sharma SK, Smith-Rohrberg D, Tahir M, Seith A. Radiological manifestations of splenic tuberculosis: a 23-patient case series from India. Indian $\mathrm{J}$ Med Res 2007;125:669- 78.

6. Ramakant Dixit, Manoj Kumar Arya , Mukesh Panjabi. Clinical profile of patients having splenic involvement in tuberculosis. Indian J Tuberc 2010; 57:2530. 
7. Batra. A, Sarma. D and Paul. S.B. Sonographic appearances in abdominal Tuberculosis. J Clin. Ultrasound. 2000; 28: 233-45.

8. Laing, F.C., Filly, RA. and Gooding, G.A.W. Ultrasonography of the spleen. In Alimentary tract radiology. Margulis, A.R. and Burhenne, H.J. 4th Edition, St.louis, C.V. Mosby Company, 1989

9. Suri R, Gupta S, Gupta SK, Singh K, Suri $\mathrm{S}$. Ultrasound guided fine needle aspiration cytology in abdominal tuberculosis. $\mathrm{Br} \mathrm{J}$ Radiol 1998;71:723-72.

10. Meshikhes AWN, Al-Momen SAM. Laparoscopic diagnosis of splenic tuberculosis. Surg Laparosc Endosc Tech 2006; 16: 355-356

11. Chen XZ, Peng B. Clinical diagnosis and treatment for splenic tuberculosis. Huaxi Medicine 2008; 23: 114

12. Porcel-Martin A, Rendon-Unceta P, Bascunana-Quirell A, et al. Focal splenic lesions in patients with AIDS: sonographic findings. Abdom Imaging 1998;23:196200. 